\title{
Transformaciones en COMUnidades Maya-Mam DE Huehuetenango, GuATEMALA: Flujos Migratorios Y DISCURSIVOS ${ }^{1}$
}

\author{
Andrea Álvarez Díaz
}

Resumen: Analizar las dinámicas familiares en contextos pluriétnicos, requiere de un abordaje que asuma la complejidad de la realidad social. Así, en un contexto de transnacionalización $y$ de importantes movimientos de circulación de grupos sociales, de imaginarios colectivos y de información, uno de los desafíos para la antropología se sitúa en torno al enriquecimiento de la categorización dicotómica, indígena/ladino. Este trabajo describe, en un municipio maya-mam de Guatemala, la presencia de nuevas condiciones de reproducción generacional en el marco de las redes de relaciones sociales, considerando las prácticas sociales y los discursos que se vehiculan. Esto es, en términos de prácticas sociales, se describe la densidad de flujos de circulación de sujetos en redes de determinados espacios socioculturales geo-referenciados: desde y hacia la comunidad, desde y hacia los centros urbanos nacionales, a los espacios productivos agrícolas temporales, y a los empleos ilegales en el extranjero.

Andrea Álvarez Díaz, maestra en Desarrollo Rural por la Universidad Católica de Temuco, Chile, actualmente cursa el Programa de Doctorado en Antropología Social, en el Instituto de Investigaciones Antropológicas de la UNAM. Temas de especialización: salud y pueblos originarios, en particular: salud intercultural en comunidades mapuche, Chile, Violencia doméstica en comunidades mayas de Guatemala. Correo electrónico: andreaalvar@gmail.com.
Abstact: In order to analyze family dynamics in multiethnic contexts, one needs an approach that considers the complexity of social reality. In this sense, one of the challenges for anthropology consists in enriching the indigenous/ladino categorization, in a context of growing transnationalization and global movements of social groups, social imaginaries and information. This paper describes, in a maya-mam Guatemalan town, the new conditions of generational reproduction within social relation networks. In terms of social practices, we describe the density of population flow of certain networks in socio-cultural spaces geo-referred such as, from and to national urban centers, from and to the community, towards temporary agricultural productive spaces, and towards illegal jobs in foreign countries. In this network of population flow, of going and coming, we examine how some social discourses propagated, in a particular territory, the town of Colotenango, produce discursive spaces in whose gaps social subjects and their speeches circulate.

Enviado a dictamen: 09 de enero de 2010 Aprobación: 05 de mayo de 2010 Revisiones: 1 
En esa red de movimientos, de iry venir, se examina cómo es que en un territorio determinado, como el municipio de Colotenango, los discursos sociales que alli transitan, generan espacios discursivos entre cuyos intersticios circulan los sujetos y sus hablas. Así, asumiendo la realidad sociocultural como redes de relaciones sociales tanto simbólicas como materiales, se identifican tres sujetos sociales que se constituyen en "nudos" de ese entramado y que facilitan el tránsito entre esos espacios, así como la circulación del poder y contrapoder en los espacios sociales y discursivos.

Palabras clave: Migración laboral, género, discurso social, sujetos sociales, poder/contrapoder.

\section{Introducción}

E las investigaciones realizadas sobre género y migraciones en México y EU (Ariza, 2007; Hondagneu-Sotelo, 2007), se ha tendido a modificar la creencia de que la migración genera efectos emancipatorios para la mujer. Efectivamente, se reconoce en la actualidad que los procesos migratorios tienden a generar "reacomodos de las fronteras de género" en nuevos escenarios, los que podrían eventualmente traer ganancias relativas para las mujeres (Ariza, 2007).

Lo que he podido apreciar a través de mi investigación de campo sobre violencia y conflicto conyugal en el municipio de Colotenango, Guatemala, es que, junto con importantes flujos migratorios, se están efectivamente configurando nuevos escenarios, en los que hombres y mujeres mayas-mam van negociando, de manera cotidiana, los significados sobre las relaciones de género. Junto a los procesos migratorios (a escala nacional e internacional), se aprecian discursos que fluyen entre los actores de la comunidad que van construyendo representaciones o imaginarios sociales (Castoriadis, 1975; Baeza, 2000) que favorecen la configuración de estos nuevos escenarios de género.
Thus, considering the socio-cultural reality as a framework of symbolic and material social relations, we identify three social subjects who constitute the "knots" in this network, and who help the movement of people between those spaces, as well as the circulation of power and counter-power in the social and discursive spaces.

Keywords: Working migration, gender, social discourse, social subjects, power and counter-power.

Así, entonces, para analizar estos nuevos escenarios, podemos identificar dos niveles de movimientos relevantes: el tránsito de personas (o procesos migratorios), que constituyen sin duda fuentes de transformaciones sociales y culturales, y el tránsito de discursos (ligados a la conformación de imaginarios), propiciado por diferentes sujetos sociales relevantes, entre los que se analizarán aquí sólo algunos. A continuación, se presenta una descripción de los flujos de desplazamiento de personas, que se han ido superponiendo en el nor-occidente de Guatemala, y en particular, en el municipio de Colotenango, para discutir, luego los dinamismos y transformaciones de una comunidad mam, a través de algunos "nudos" del entramado social, que permiten que sujetos y discursos circulen en sus intersticios.

El objetivo de este artículo es entonces, proponer algunos elementos para un análisis denso del entramado social (Geertz, 2000) de las comunidades maya-mam de Colotenango, Huehuetenango, considerando no sólo los flujos migratorios, sino que añadiendo la forma en que con los primeros, transitan también flujos discursivos ${ }^{2}$, siendo ambos portadores de transformaciones en las comunidades maya-mam que describo. Por flujos discursivos se hace referencia a argumentos movilizados en un universo discursivo, 
que se reproduce en un determinado campo de fuerza sociales, políticas e ideológicas, en el que diversos actores (agentes de discurso) están dotados de poder (Álvarez, 2007). Se adopta, de este modo, la noción foucaultiana de universo discursivo, entendiendo que un conjunto de discursos circulan en un momento histórico determinado, sobre ciertas temáticas (por ejemplo, sobre la la migración, sobre la educación y sobre el género, en el caso de este trabajo), en una sociedad determinada. Esto implica además que los discursos sociales permanecen a través del tiempo y que están disponibles para reaparecer en nuevos textos discursivos (Foucault, 1971).

Así, los elementos argumentativos se insertan en la dimensión social de la realidad, con sus protagonistas, por relaciones de poder (poder material y simbólico), en un contexto socio-histórico determinado (Álvarez, 2007). En este sentido es que los flujos discursivos que aquí se analizan, como todo acto de lenguaje opera en el "orden del discurso" y no en el "orden de las cosas", aunque también construyen realidad (Berger y Luckmann, 1987). Con todo, "el discurso no moviliza ni los hechos, ni los objetos mismos de la realidad, sino que construyen representaciones de los sujetos, de los objetos, de las acciones y de las relaciones entre ellos" (Álvarez, 2007: 60-61). Entonces, los flujos discursivos son una construcción ideológica que es movilizada por algunos actores sociales, encontrando asidero en miembros de la población, construyendo un imaginario social compartido, reproducido por dichos actores (Álvarez, 2007).

Intentando ver más allá de la dicotomía tradición modernidad, en la red de relaciones sociales que se entretejen en los niveles de lo local, lo regional, lo nacional, me planteo algunas interrogantes: ¿qué discursos y cuáles prácticas sociales se entretejen? ¿Entre éstos, cuáles son aquéllos que facilitan que mujeres y hombres puedan negociar sus conflictos conyugales? $\mathrm{O}$, si se quiere, dicho de otra manera: ien cuáles intersticios del entramado de relaciones sociales local/global se expresan los recursos para mediar y resolver los conflictos conyugales de manera no violenta? Estas interrogantes, que intento responder en una investigación más amplia que realizo sobre violencia y conflicto entre los cónyuges, son las que me han llevado a la necesidad de asumir la complejidad y dinamismo de la realidad social a cabalidad. Esto es, enriquecer la categorización dicotomizada maya/ladino buscando dar cuenta de los nuevos escenarios que se generan y que permiten la configuración y negociación de las relaciones de género, que es lo que me interesa presentar en este trabajo.

\section{Movimientos migratorios desde y hacia comunidades maya-mam}

La migración de los mames de Colotenango no es un fenómeno reciente. Ya a fines de los años 50, el pueblo mam de Colotenango, situado en el altiplano noroccidental fue caracterizado por Valladares (1957) como un pueblo eminentemente agrario, con un desarrollo de industrias menores, cuyos dueños eran ladinos del sector. La principal ocupación del coloteco mam, en ese entonces, era el cultivo de la escasa tierra que poseía y, una vez terminados sus cultivos, el empleo de mano de obra como jornalero para los dueños de mayores porciones de tierra.

Como describe Valladares, en su etnografía El hombre y el maíz:

De manera mayoritaria, el campesino (mam) posee una cantidad de tierra, cuyos cultivos no cubren el consumo de la familia (...) razón por la cual se ve en "la necesidad de ir a trabajar a las fincas de la costa durante los últimos meses del año, que es cuando cesan las labores agrícolas en la región; y, con el dinero ganado hacerle frente a la situación durante los primeros meses de la estación lluviosa, hasta que puedan comer los primeros elotes de agosto (1957: 61). 
Históricamente, los mames del departamento de Huehuetenango fueron viajeros comerciantes. Efectivamente, el copalfuecomercializado por los mames en los años cuarenta y cincuenta intercambiándolo con indigenas de Chiapas por maíz y frijol (Hernández, 2009).

Como en otras áreas rurales de Guatemala, la pauperización de la población maya-mam se ha relacionado directamente con la dinámica de descomposición de la economía campesina (Ordóñez, 1990; Castillo, 1993), determinada por procesos históricos ligados al acceso y a la tenencia de la tierra. Efectivamente, las tierras aptas para la producción han sido arrebatadas al pueblo maya-mam desde la invasión española, relegando a los mames a habitar y reproducirse en regiones montañosas y selváticas en condiciones de pobreza.

Una característica histórica de la formación social guatemalteca es el profundo racismo que se manifiesta en una serie de expresiones de discriminación hacia la población indígena (Castillo, 1993). El racismo, entendido no sólo como actitudes y comportamientos de los grupos sociales no-indígenas, sino como una ideología, se ha convertido en el soporte superestructural de procesos de marginación, explotación, manipulación y abuso de la población maya; racismo que incluye de hecho el contenido y orientación de las políticas de Estado.

Ante estos procesos socio-históricos de marginación y usurpación de tierras, los habitantes mam del altiplano occidental combinan en la actualidad dos estrategias para alcanzar su sobrevivencia: la agricultura de subsistencia y la migración en busca de un empleo que les permita un ingreso monetario. La importancia que ha ido adquiriendo la migración como estrategia de reproducción de la unidad doméstica, es cada vez mayor y sus modalidades se han ido diversificando históricamente, describiéndose movimientos de población, en tres momentos históricos diferenciales: a) durante la primera mitad del siglo XX, la migración estacional hacia la región del Soconusco, Chiapas, en torno a la actividad cafetalera, como único flujo con alguna importancia; b) la migración por razones políticas que se produce durante los años ochenta, producto de la agudización extrema de la represión ejercida por el Estado durante la guerra interna en Guatemala; y c) de manera paralela, en torno a la misma década, la migración masiva que se inicia hacia Estados Unidos y México, principalmente en calidad de migrantes indocumentados (los así denominados "mojados") (Ángeles, 2002).

a) La migración hacia las fincas cafetaleras de la costa y sierra de Chiapas se constituye, desde los primeros decenios del siglo pasado, en torno a una estructura parasitaria de gestión de la fuerza de trabajo (habilitadores y enganchadores) casi siempre ladinos que establecían relaciones de "protección y avasallamiento" de "sus indios" (Castillo, 1993). La presencia de trabajadores guatemaltecos en las labores del café fue incrementándose, y a partir de los años cincuenta y sesenta las migraciones estacionales toman mayor auge e importancia (Ángeles, 2002). Aunque no es posible determinar su cantidad en la actualidad, se puede establecer que la mayoría de los trabajadores temporales proceden del altiplano occidental guatemalteco (Castillo, 1993), ${ }^{3}$ que es donde se presentan los más bajos niveles de producción de subsistencia, los menores índices de rendimiento de los cultivos tradicionales, la mayor concentración demográfica, los mayores niveles de presión sobre la tierra, la tierra menos fértil y las mayores condiciones de pobreza entre la población rural del país.

Aunque existen importantes diferencias entre las condiciones laborales que se ofrecen en las unidades privadas y ejidales, en general los trabajadores migrantes expresan su preferencia en dirigirse a México, más que a las plantaciones de su país, debido a diferentes motivos (como la inclusión de la comida como prestación, condiciones de alojamiento, obligatoriedad de prestación de servicios médicos y un eventual 
salario mayor, que lo que obtendrían en Guatemala). Sin embargo, la relación salarial de trabajo temporal es altamente funcional y estratégica para la empresa agroexportadora del Soconusco chiapaneco donde se ha observado la reducción en términos reales del pago para la reproducción de la fuerza de trabajo (salario), con jornadas más largas y relativa intensidad del trabajo y ahorro en pago de prestaciones laborales y de seguro social (Ordóñez, 1990).

b) Durante los años sesenta, se generan en Guatemala condiciones de crisis económica y política en el país, que derivan en un enfrentamiento nacional armado, a partir de finales de los años setenta. Así, se desataron acciones de contrainsurgencia y de represión masiva hacia la población civil, cuyo periodo más agudo ocurrió entre los años ochenta y uno a ochenta y tres (Ángeles, 2002; Duarte y Coello, 2007), principalmente dirigida hacia los mayas. El pueblo maya fue doblemente castigado, tanto como sujeto social, en rebeldía ante la represión e injusticia social, así como sujeto étnico que el Estado guatemalteco, a través del ejército y las PAC (Patrullas de Autodefensa Civil) sistemáticamente buscó exterminar; tal es así que se habla de "etnocidio".

Ante un nivel de represión ejercida por el Estado guatemalteco, sin precedentes en toda América Latina, se iniciaron masivos desplazamientos de familias mayas e incluso comunidades enteras en diversas direcciones. En comunidades maya-mam, "algunas de las víctimas de la represión se movilizaron a zonas montañosas y permanecieron en los refugios por tiempos prolongados; otros se desplazaron a centros urbanos, principalmente a la ciudad de Guatemala engrosando las amplias zonas de miserias existentes; $y$ otros pudieron cruzar fronteras como la mexicana solicitando apoyo a la comunidad internacional" (Castillo, 1993).

Aunque la cifra total de refugiados reconocidos alcanza las 45 mil personas que fueron atendidas por agencias oficiales, existe un número indeterminado de refugiados "no reconocidos" que se alojaron en forma dispersa, en zonas rurales y núcleos urbanos de México, que no cuentan con reconocimiento ni apoyo de instancias oficiales. Se ha documentado las características de la población migrante hacia el exilio, "reconocida como refugiada", siendo en su mayoría campesinos del nor-occidente del país, de alguno de los grupos étnicos que ha habitado secularmente la región. Como lo reporta Castillo (1993), "cifras del programa oficial IMSS-COPLAMAR, declaran que solamente 12\% de los refugiados que se asentaban en campamentos de aquella época hablaban español, siendo las lenguas predominantes entre los refugiados, el kanjobal en un $40 \%$ y el mam en un 26\%, con presencia de los otros idiomas, tales como el chuj, jacalteco, chol, lacandón, quiché, cackchiquel y kekchî". Por último, se registra una proporción muy menor de refugiados a los territorios de Canadá y Estados Unidos, que serán sin embargo significativos en la posterior inserción de migrantes transnacionales en estos países (Duarte y Coello, 2007).

c) Gloria es soltera, tiene 29 años, es oriunda de la aldea de El Granadillo del municipio de Colotenango, Huehuetenango. Vive con su familia de origen, junto a sus padres, sus tres hermanos menores, una hermana soltera, su cuñada, su abuelo paterno y tres sobrinos. De sus 14 hermanos, dos están trabajando en Los Ángeles, y tres hermanas se han ido ilegalmente a Cancún, dónde trabajan como trabajadoras domésticas. Clara, la menor de ellas, de 19 años, cruzó la frontera con su bebé de 11 meses, después de haberse separado de su marido y regresar desde la casa de sus suegros a la de sus padres, de acuerdo al principio de patrilocalidad que se practica en las comunidades maya-mam.

La situación de la familia de Gloria no es la excepción entre los mam de Colotenango. Como otras mujeres mam, ya sean casadas, solteras o separadas, Gloria tiene que enfrentarse como parte de su proyecto de vida a la disyuntiva de viajar, o no, al norte, como sus hermanos y hermanas:

...mi hermano, que es el primer hijo de mis padres, él casi no estuvo en la casa, tenía como 16 años cuando se 
fue a los Estados Unidos... después él se regresó, tenía como 22, 23 años cuando regresó...y yo creciendo... él casi no estuvo en la casa, cuando regresó del norte, se fue a trabajar en la ciudad, en Guatemala (...) Cuando salí entonces (de la chamba) pensé de ir al norte; eso es mi idea, entonces le dije a mi mamá, (pero) ella me dijo, "iPorqué? ¿Acaso Usted no está pensando de casar?" "No tengo idea de eso, de casarme, no... lo que yo quiero ahorita es construir una mi casa, eso es... Por eso pensé de ir al norte... Ella está de acuerdo, pero mi hermano el más mayor (el que está allá), él si no quiere. - “iPara qué vas a venir aquí? Vas a venir a sufrir. Tal vez Usted piensa que uno está aquí y no está sufriendo, pero ahí lo vas a ver si te venís. Mejor quedate en la casa" (...) Cuesta conseguir trabajo, también las mujeres trabajan en el campo, en el tomate...saber cómo es... Ahorita ya no estoy pensando en ir, ya no. Como él me dijo que no... él me estaba diciendo, "mejor andate a cuidar mi casa, te voy a mandar dinero." Estoy pensando en hacer eso, para no salir más allá...en la Costa tal vez voy... (Entrevista, octubre 2007).

La cantidad de migrantes hacia los Estados Unidos ha aumentado muy significativamente en los últimos 10 años, con una incorporación notable de dos grupos sociales en los últimos tiempos: el de las mujeres y el de los mayas (Oficina Internacional de Migraciones, 2007). Se registra para el año pasado un total de 1 millón 539 mil 987 hombres y mujeres guatemaltecos que residen en el exterior (lo que equivale a 11.2\% de la población total); cifra que ha venido aumentando desde el año 2002 (cuando alcanzaba 10.5\%).

Aunque emigran mayor cantidad de hombres que de mujeres ( $73.4 \%$ y $26.6 \%$ de los migrantes, respectivamente), ambos grupos mantienen constantes flujos migratorios de manera creciente. Con relación a la procedencia de los migrantes, 55.8\% emigra de las áreas rurales del país mientras $44.2 \%$ proviene de áreas urbanas, al igual que en años anteriores. Por otra parte, los departamentos más expulsores de guatemaltecos hacia el exterior son: Guatemala (20\%), San Marcos (10.1\%), Huehuetenango (9\%) y Quetzaltenango (6\%).

El aumento tan significativo y constante en el flujo de migrantes indocumentados a Estados Unidos radica básicamente en la demanda específica por parte de los mercados de trabajo del polo receptor, junto a la necesidad de flexibilizar y desregular los procesos productivos y laborales. Por las características de alta vulnerabilidad de los migrantes indocumentados, se hace más fácil su sobreexplotación y retención por parte del empleador, ante la dificultad que tendrán si quieren moverse a otro sector económico de actividad (Aragonés y Dunn, 2005).

Como describen Aragonés y Dunn (2005), las cifras que reporta el American Urban Institute en el año 2004, sobre migración indocumentada, alcanzan los 9,3 millones de personas, lo que representa 26\% de la población extranjera de ese país. El sueldo que se le paga al trabajador indocumentado es muy inferior al que se le paga al nativo, e inferior que el del migrante documentado; sin embargo, por supuesto, sigue siendo mayor que lo que podrían ganar en sus respectivos países (Aragonés y Dunn, 2005). Así, esta condición sigue siendo un atractivo de extracción de fuerza laboral y una justificación para la sobreexplotación por parte de los empresarios para mantener los salarios tan bajos.

En estas circunstancias, las redes sociales que tienden a establecerse entre migrantes latinoamericanos adquieren una gran relevancia ya que ayudan a disminuir el costo social y el riesgo personal ante la alta vulnerabilidad a la que están expuestos a diario los trabajadores indocumentados.

\section{Dinamismo y transformaciones desde una perspectiva local/global}

Dar cuenta de manera densa de la complejidad de una realidad social nos pone ante el desafío intelectual de integrar diversidad de flujos que se tensionan 
en movimientos continuos. Así, desde un territorio determinado, el municipio de Colotenango, entendido como parte de la comunidad maya-mam, de carácter más amplio, se visualizan tanto flujos migratorios (léase de personas), como flujos discursivos y de imaginarios sociales.

En un primer momento, se han descrito, en términos de prácticas sociales, los flujos de circulación de los sujetos migrantes, en las redes de determinados espacios socioculturales geo-referenciados: desde y hacia la comunidad, desde y hacia los centros urbanos nacionales, a los espacios productivos agrícolas temporales, y a los países de exilio en tiempos del conflicto armado interno, y a los empleos ilegales en el extranjero.

A continuación, además de este entramado de movimientos de personas descrito, se examina, cómo es que en el territorio de Colotenango, se vehiculan discursos sociales entre cuyos intersticios circulan los sujetos y sus hablas.

Brevemente, y a modo de líneas de indagación se identifican sujetos sociales que se constituyen en lo que llamaremos "nudos" de este entramado social (para mantener la metáfora del "tejido social") y que facilitan el tránsito entre diferentes espacios discursivos. Se han elegido, para discutir en este trabajo, a tres sujetos relevantes en estos tránsitos de grupos sociales, de imaginarios colectivos y de información: por una parte la polémica figura del "coyote", que de manera ilícita y con una motivación economicista a ultranzas, ayuda a los "mojados" a llegar a su destino; luego, la dinámica figura del/la joven "maestro"/a bilingüe, que ha ido paulatinamente integrando a los idiomas mayas y al castellano, los códigos de la Internet y de la proyectología social; y por último, la figura de la "promotora-mujer" de organizaciones no-gubernamentales que hace suyos los derechos universales de la mujer y que debe lidiar con los feminismos liberales y con las demandas colectivas de reconocimiento de los pueblos mayas.
No se tratará entonces, en este texto, de analizar a la diáfana figura de la monjita, ni la figura tradicional de la partera, o del carismático dirigente político o campesino, que se han tendido a describir como figuras monolíticas, portadoras de un discurso compacto. Tanto aquéllas, como las que proponemos analizar en este texto, se constituyen en realidad como figuras híbridas, reñidas con una pertenencia cultural o identitaria única, y que en la traducción de un código cultural a otro, tiendan a traicionar lealtades y códigos de pertenencia monolítica, en el entendido que "traducir, de alguna manera, conlleva traicionar".

El análisis de la circulación de los diferentes discursos, se realiza en torno a tres imágenes, que son un medio para graficar las tensiones en torno a diferentes temáticas relevantes para los miembros de la comunidad, a saber: la migración, asociada a la figura del "coyote", la educación y el bilingüismo, asociados a la figura del maestro intercultural, y el género y los derechos de la mujer, asociados a la figura de la promotora local de ONG.

\section{El coyote y el discurso sobre la migración}

Tal vez el más sencillo de analizar sea la figura/nudo del coyote, por la alta carga moral que conlleva lo ilícito de su trabajo, la forma unilateral en que establece las tarifas (debiendo algún familiar incurrir en deudas para su financiamiento que será devuelto con el trabajo del propio migrante), y los malos tratos, denigraciones y atropellos a la dignidad humana, que se han reportado en numerosos medios de comunicación y de denuncia. No es por nada que los zapatistas, cuando han tenido oportunidad, han hecho justicia popular, devolviendo a los migrantes centroamericanos el dinero pagado en forma anticipada al coyote, y han "liberado" a éstos de su tutela, sugiriéndole a los migrantes que regresen a sus pueblos, alertándolos de los peligros que acechan al migrante indocumentado, tanto en México como en Estados Unidos. 
Sin embargo, la imagen que existe de este "eslabón de la cadena migratoria" en las comunidades mam que he visitado, es de cierto respeto y admiración ante los riesgos a que se expone, y antes que nada, de sobria necesidad ante las expectativas de mejoría económica que significan para la familia y la comunidad del futuro "mojado", si logra enrolarse en el norte como trabajador. La narrativa que se construye en las comunidades mam sobre el paso del desierto, incluye la puesta en escena de un sujeto de enunciación que siendo varón, asume en el imaginario colectivo, características heroicas, asociado a su rol de género, que permiten a los mojados llegar a buen puerto.

De alguna manera coyote y mojado son cómplices de la aventura que significa desafiar no sólo a la "migra" de los países del norte, sino también a los peligros naturales del desierto, muchas veces minimizados, como el riesgo de deshidratación, de hipertermia en el día, de hipotermia en la noche, y del cansancio de las largas caminatas. Todo lo cual ha significado un proceso de conformación de una "cultura del cruce" (Meneses, 2007), tanto por parte de los migrantes como por parte de las organizaciones especializadas en introducir a migrantes indocumentados por zonas desérticas. Quien conozca los desiertos de Yuha, Altar, Organ Pipe o el Sásabe, por mencionar sólo algunos, sabrá que la espléndida belleza de sus paisajes esconde algunas de las rutas más transitadas de la migración clandestina, y a veces lamentablemente los parajes más mortíferos para los migrantes que viajan al norte sin visa ni pasaporte.

Sin embargo, la contradicción fundamental contradicción en apariencia-, no radica sólo en el paisaje sino en el trasfondo social y económico del proceso de la globalización, ya que por una parte se promueve la libre circulación de capitales y mercancías, y por otro lado se reprime, incluso con la muerte a través de estas medidas migratorias que rayan en el terrorismo, la libre circulación de trabajadores, o de su fuerza de trabajo como mercancía de éstos. Las cifras de la patrulla fronteriza son elocuentes: en el período 1994-2003, se realizaron 13 millones de detenciones (algunos fueron detenidos más de cuatro veces) y se contabilizó desde 3000 hasta 4000 inmigrantes muertos o desaparecidos, en la línea entre México y Estados Unidos (Meneses, 2007). Así, la vida del migrante está en manos de los únicos expertos a priori: los "coyotes".

\section{El maestro bilingüe intercultural y el discurso de la Educación}

Una figura no menos relevante en las comunidades mam del altiplano de Los Cuchumatanes es la del maestro bilingüe intercultural, así denominado porque asegura que los niños y niñas mames cursarán la educación pre-primaria, primaria y básica transmitida tanto en su idioma materno, como en el idioma oficial del Estado-nación (el castellano). En las comunidades mam de Colotenango, 95\% de la población es rural, y 95\% es mam (Municipio de Colotenango, 2003). El Plan de Desarrollo Municipal evalúa para el año 2002, en $51 \%$ el grado de monolingüismo en la población mayor de 15 años. Aunque la cifra no se desagrega por sexo, el documento destaca que se presenta un "elevado número de monolingües, en su mayoría mujeres". Hace una década, un estudio de la situación de las mujeres en el municipio (Ceiba-Cedes, 1998) estimaba en $97 \%$, la proporción de mujeres mayores de 15 años, monolingües, y en 3\% la proporción de mujeres bilingües; proporción que tendía a invertirse en el caso de los hombres del municipio. A esta pérdida del uso del idioma mam ha contribuido notablemente la escuela oficial, considerada por los padres de familia como el espacio donde sus hijos van a aprender el idioma español (Mendizábal, 2007) y puedan así tener mejores expectativas de vida, y poder desenvolverse mejor en la ciudad cabecera y en la capital, y en las instituciones del Estado y del mercado.

Por otra parte, algunas dificultades administrativas del sistema educativo nacional ha significado que en las aulas de las escuelas de las aldeas mam los profesores 
bilingües hablen castellano y kaqchikel, o español y k'iche', o kanjobal, chuj, poptí, awacateko. Situación que tiende a subsanarse en la medida en que el maestro bilingüe se hace trilingüe, u obtiene su traslado a través del sistema de postulación a cargo vacante, por lo demás muy cuestionado por la falta de transparencia y de rigurosidad en la selección de los/as maestros/as.

Ahora bien, la existencia de la figura del maestro bilingüe intercultural podría permitir una suposición en la realidad multicultural guatemalteca, que es que los niños y niñas mames tienen acceso a un programa de educación bilingüe que integra los contenidos programáticos mínimos de la educación formal a los contenidos culturales, las metodologías pertinentes culturalmente, la historia del país desde la óptica de la pluriculturalidad, y la perspectiva de la naturaleza y del mundo desde su cosmovisión maya-mam. Sin embargo, las experiencias que puedan reportarse que tiendan a incorporar elementos de interculturalidad en el aula y en la relación maestro-alumno/a, son iniciativas basadas en el esfuerzo personal o colectivo de maestros y maestras cuestionadotes de su propia formación en el sistema educativo guatemalteco, altamente burocratizado y reproductor de la discriminación social.

El problema tiende a ser estructural en la medida en que se observa la ineficacia de los programas de Educación Bilingüe Intercultural en los contenidos y en los textos educativos (Mendizábal et al., 2007). Como lo concluye Cojtí (2007) el sistema educativo no ha empezado a difundir la multiculturalidad y la interculturalidad vehiculados por la Reforma Educativa prevista por los Acuerdos de Paz, sino que continúa difundiendo el nacionalismo homogenizador con una representación de los mayas como campesinos, tradicionales, analfabetos, pobres, y en forma peyorativa, como haraganes, ignorantes y "raros".

En términos simbólico-estructurales, la figura del maestro bilingüe intercultural es un sujeto producto y productor de discurso en la institucionalidad educativa, tanto a nivel local como departamental y nacional. En esta institucionalidad coexisten, de manera dinámica, discursos e imaginarios sociales en transición desde un cierto "nacionalismo segregador" hacia un "asimilacionismo universalista" o hacia un "multiculturalismo individual" (Cojtí, 2007), que reconociendo la diversidad cultural la limita al ámbito de los individuos y no de los pueblos.

\section{La promotora de ONG local y el discurso de género}

La figura/nudo de la promotora de ONG es la que con mayor centralidad vehicula los flujos discursivos sobre género construidos a nivel global y local, ya que su labor promueve a la vez tópicos y estrategias de la agenda de prioridades de las agencias de los países del norte. Efectivamente, en Guatemala junto con reconocer la confianza que el movimiento de mujeres ha depositado en los organismos internacionales y en su capacidad para producir cambios reales en la situación de la mujer, desde hace un tiempo ya las organizaciones de mujeres han venido cuestionando esta capacidad. Como lo señala Mercedes Cañas, en su análisis sobre el movimiento feminista en Guatemala, y su relación con las instituciones nacionales e internacionales (Trujillo, 2004), el hecho de "haber transcurrido bailando cierto tiempo al son de ellos" hizo que se acumulara en el movimiento de mujeres: la experiencia de tener un techo en las discusiones, reconocer que se depende del financiamiento de la cooperación para continuar interviniendo e investigando, y por último restricciones a la posibilidad de cuestionar el rol del Estado, basado en la necesidad de tiempos necesarios para la realización de cambios institucionales.

La figura de la promotora ha tenido que vincular el discurso sobre el respeto a los derechos individuales de la mujer, los derechos reproductivos de la mujer, y en general la temática de género, de manera no exenta de conflictos, con su propia pertenencia étnica 
a un colectivo con derechos sobre el territorio, a una institucionalidad social, a un cuerpo de conocimientos legados de generación en generación, aún a través de la comunidad extensa, o transnacional.

Las perspectivas etnocentristas del feminismo han hecho eco en algunas agencias de cooperación que descalifican como limitadas aquellas agendas políticas que no ponen al género en el centro de sus intereses. Así, se justifica la necesidad de hacer un trabajo de "concientización" que acerque a las mujeres a la verdadera conciencia feminista, cuando éstas han optado en las comunidades por hacer un trabajo junto con los hombres en organizaciones mixtas, que combinan demandas de reconocimiento con las de distribución (Hernández, 2008).

Lo que se puede constatar en las comunidades maya-mam, como en otras comunidades indígenas del continente, es que las mujeres organizadas han hecho suyas las demandas de reconocimiento de los derechos culturales, políticos y sociales del pueblo maya. Así, tanto los pueblos originarios como las mujeres han puesto en evidencia las falacias del discurso republicano sobre la igualdad, ya que en nombre de esta igualdad y de la necesidad de construir una nación moderna, homogénea y mestiza, se negó a los pueblos indígenas el derecho a hablar sus propios idiomas, se establecieron leyes sin su consentimiento, se deslegitimó la autoridad de sus instituciones político-religiosas.

Como lo indica Aída Hernández, la narrativa de la igualdad, paradójicamente, ha producido la profundización de la desigualdad (2008: 27). El compromiso retórico con la igualdad de las personas, ha imposibilitado que se destaquen las diferencias que estructuran actualmente el privilegio y la opresión (Young, 2000, citado en Hernández, 2008). Así, frente al discurso excluyente de la ciudadanía liberal, el movimiento indígena de Guatemala (así como el de Colombia y el de México) ha planteado la necesidad de vincular sus demandas políticas al reconocimiento de sus derechos culturales y políticos como pueblos y, entre esas demandas, las indígenas se han dado la tarea de incluir sus derechos como mujeres (Hernández, 2008).

La figura de la promotora en las comunidades mayamam tiende entonces a reapropiarse del discurso crítico y de las herramientas del feminismo latinoamericano, asumiendo en algunos casos la emergencia de un feminismo indígena (como en el caso del Grupo de Mujeres Mayas Kaq'la). En otros casos, rechazan el concepto de feminismo y optan por reivindicar la cosmovisión indígena y su espiritualidad, el poom, reivindicando los conceptos de complementariedad y dualidad, fuertemente criticados por el feminismo académico. En particular, un punto de tensión se ha situado en torno a la preocupación por parte de la cooperación internacional por los derechos sexuales y reproductivos. De este modo, las agencias internacionales tienden a descalificar las propuestas de las mujeres que no otorgan la misma importancia a los derechos sexuales y reproductivos de las mujeres, reproduciendo así mecanismos de silenciamiento y exclusión propios de las relaciones de poder patriarcales.

\section{Negociando las relaciones de poder entre hombre y mujeres}

A partir de lo expuesto hasta ahora, podemos señalar que, en un contexto de transnacionalización y de importantes movimientos de circulación de grupos sociales, de imaginarios colectivos y de información, se van construyendo, en la articulación local/global, una diversidad de discursos y nuevas prácticas sociales, desde las cuales las mujeres pueden negociar sus conflictos conyugales y/o familiares, en el entendido que se van reacomodando las fronteras de género entre varones y mujeres. Estas rearticulaciones de las fronteras de género se pueden evidenciar, notablemente, en los campos de la educación, de los procesos migratorios, y de los espacios de participación social y política, como se presenta, brevemente a continuación. 
Ingresar a la escuela tiene sus costos, y estos costos son diferenciales además por sexo. A través de estereotipos tales como "las mujeres no sirven para estudiar", se va añadiendo a la discriminación étnica, un componente de género que, hace que muchas mujeres ante la agresión y la humillación en la escuela por parte de maestros, maestras y compañeros y compañeras, tiendan a dejar el espacio educativo reforzando así el prejuicio étnico, de género y de clase.

El acceso a la educación para los niños y niñas colotecas fue una oportunidad a la que pudieron optar tardíamente, si se le compara con la situación en el resto del país, sobre todo, con respecto a la población ladina de Guatemala. Los niños mam que gozaron de la posibilidad de que sus padres los inscribieran en la escuela, fueron alternando sus responsabilidades laborales con las educativas, lo que de todas maneras era, en los años setenta, un espacio en el que mayoritariamente participaban varones. Así lo reporta don Chepe, maestro empírico, egresado de la primera promoción de la escuela primaria local.

Mi mamá nunca fue a la finca. Los demás hermanos tampoco. Como yo soy el primer hijo de mi papá, entonces soy el primero... y la otra hermana, es la que seguía después de mí, ella sí... fuimos a la finca. Ahora, mis demás hermanos, no. Después como a la edad de 9 a 10 años, mi papá pensó de mandarme a la escuela. Y en ese tiempo fue cuando por primera vez se abrió el colegio, ahí en el Convento, ahí en Colotenango, en el pueblo. Entonces nos íbamos aquí a pié... Salíamos a las seis de la mañana, llegábamos a las siete y cuarto a la escuela; salíamos a las doce y media, y veníamos como a las tres de la tarde aquí de regreso. Pero sí, la situación de nosotros fue dura pues. Pero gracias a mi papá, no me dio todo el estudio, pero sí me dio la primaria, sexto grado (...) En aquel tiempo casi sólo éramos hombres... mujeres casi no. Y cuando nosotros sacamos nuestra primaria, se graduó sólo una mujer con nosotros. Sólo la suegra de ella, doña María, la suegra de Marta. Juntos estudiamos, con Don Juan, Doña María y yo, fuimos los primeros, de la primera promoción (en 1970).

Los testimonios de algunos líderes comunitarios y maestros mam de la aldea El Granadillo, de Colotenango, denotan la forma en que las niñas fueron sistemáticamente separadas del espacio educativo, en las comunidades Mames.

...pero nuestra gente, en la época anterior, ellos traen esa tradición, esa costumbre que sólo el hombre es el que tiene derecho. Según dicen ellos, que las mujeres, antes, sólo que ya tienen sus 4 años, a pastorear chompipes, o ganado... o chivos. Y el niño donde es varón, a la escuela, le daban...y la niña, que se quede en la casa. La niña, en el oficio doméstico, y el niño sólo él (a la escuela)... A razón de eso dónde surge que la mujer siempre ha tenido un poquito, un nivel académico más bajo...La idea de la gente es que, como es mujer, no tanto se le da importancia...se va con el marido, dicen, porque el marido es él que vale, el que tiene más fuerza, más inteligencia. Por eso es que nos dice: "la mujer no se va a la escuela, va a buscar su marido. En cambio el hombre hay que llevarlo a la escuela porque de repente consigue un trabajo. No le dan importancia a la mujer y no consigue trabajo. Se va a casar, y ahí está el marido para mantenerlo", dice. La gente no analiza si tanto hombre como mujer, tenemos la igualdad, los derechos, las obligaciones... no lo piensan ellos así, sino que más le dan importancia al varón...en cambio a la hembra, no tanto.

Lastransformaciones hanidoocurriendopaulatinamente, tanto por parte de los padres que fueron asumiendo la necesidad de sus hijos e hijas aprendieran el código del otro, lo que significó contar con una herramienta de extraordinaria potencia. Como lo indica la académica maya, Emma Chirix, (2003: 157) "aprender el lenguaje del opresor significa capacidad para responder con 
este lenguaje. Tomar conciencia del lenguaje es desafiar el desprecio y la desvalorización, para asumir una actitud retadora y de transformación". El exdirector de la escuela local primaria de Colotenango, describe el lento proceso de incorporación de mujeres al espacio educativo:

pero tal vez se está cambiando todo eso, ya... la mentalidad más que nada la gente del área rural, ellos dicen, ahorita: "Bueno, voy a mandar a mi hija, voy a mandar a mi hijo a la escuela" (...) Desde un principio empezó varias mujeres. Pero una se graduó en 1970... sacó su sexto grado de primaria. Las otras se desertaban antes de terminar sexto. Pero llegó un momento, yo diría que por ejemplo en el 73, 74, ya casi, casi era el mismo número de mujeres y hombres, que estudiaban... pero así era también, ya salían... porque miraban que los primeros que habían salido ya tenían trabajo. Hace un mes yo estuve en una reunión, se juntaron todos los maestros y había una estudiante mía, que ya tenía 23 años de ser maestra. Eso muestra que sí había ya mujeres, y había una lucha entre hombres y mujeres en ese tiempo. Los que entraron ahí, los que supieron aprovechar, sí salieron adelante, a la par del hombre.

Por su parte, Somaya, promotora de ONG local, y lidereza mam explica que en Colotenango, las mujeres casadas tienden a no asumir los cargos de representación propuestos para evitar conflictos con sus cónyuges, a quienes tienen que pedir permiso para asistir a las reuniones. La significación social con respecto a las mujeres casadas que participan socialmente, tiende a asociarla a una "mala mujer, que está dominando a su marido, su esposo", lo que genera en el varón una actitud reticente con respecto a la participación de la esposa en las organizaciones. Además, reitera la promotora, los hombres tampoco aceptan que las mujeres se capaciten porque tienen miedo, "aún más ahora, con el divorcio, con el cuidado de los niños”, y ese miedo hace que rechacen la posibilidad que la mujer se forme en espacios de capacitación.

A partir de su experiencia en trabajo social y trayectoria como dirigente de base, sostiene que en Colotenango, se puede llegar a que las mujeres participen, en la medida en que la metodología que se utilice en el proceso, incluya tanto a hombres como a mujeres:

porque si seguimos dando la capacitación sólo a mujeres, siempre las mujeres cuando se juntan (con los hombres), no opinan; cuando están solas sí. Entonces yo he puesto mis propuestas aquí (en la ONG) y en otras organizaciones, que se empiece una capacitación mixta, dónde va quitando el miedo y también hacer campañas de sensibilización a hombres por cada comunidad. Y también no sólo con los Cocodes (Comités Comunitarios de Desarrollo), sino también con los hombres de cada comunidad.

En términos evaluativos, la dirigenta señala que:

con lo hecho, las mujeres están ocupando cargos, hablando dentro de un grupo. Es un poco diferente que hace cinco o seis años, que las mujeres ni salían de la comunidad. Ahora, por ejemplo, las comadronas llegan a capacitarse a sus cursos, que antes no salían. Y las mujeres de la comunidad, las liderezas ya pueden participar, y cuando hay una reunión le avisan a sus grupos. Esto ya está cambiando, está cambiando...Con esta práctica que están haciendo, yo creo que también los hombres se van a acostumbrando y aprendiendo esa situación.

Somaya ejemplifica estos cambios que se vienen generando en la relación entre hombres y mujeres, a partir de su propia experiencia personal con su esposo, quien a pesar de la presión social ha podido establecer una equidad de género en los roles domésticos y públicos: 
En mi caso pasó eso, de que mi esposo él entendía de que las mujeres tienen el mismo derecho, que la mujer son las mismas que los hombres. Y él cuando a poco nos casamos, sí, él no me agarraba dónde yo iba. El siempre me daba oportunidad de participar, de hablar, de salir en lugar a otro lugar, pero lo que yo vi allí, de que hay muchos hombres de que comentaban: "El ya no sirve, de que es la mujer que domina." Un montón (de cosas) que dicen los hombres de la comunidad. Y yo no es que le diga que mi esposo no sufrió; sí sufrió con eso...porque él estuvo defendiendo: "Que no es así". Y ya cuando estaban mis niños pequeños, le dejaba a mis hijos, él lo lava sus ropas, y la hacen la comida de él. Entonces ahí es donde si, los hombres comentaban: "que en lugar es él que salía, en lugar... ¿cómo es posible que él se deje en la casa?". Entonces hay una presión muy fuerte. Pero cuando los hombres ya te entienden, ya saben como es la participación de las mujeres, pues, ya van entendiendo. Ahora ya los hombres no le dicen nada, porque ya se le quitó las ganas de hablar mal de él. O sea el objetivo de los otros hombres es lograr que uno ya le hace caso. Pero en este caso, pues mi esposo no dio caso.

A partir de su propio testimonio, Somaya reflexiona sobre lo dicho y reconoce que "a veces yo me pongo a pensar, y es lo que me he preguntado de que hay momentos que él no dice... pero se siente algo presionado por otros... Es un poco duro, difícil".

Por otra parte, en el caso de la experiencia migratoria, ya instalada en el municipio de Colotenango, la relación con el cónyuge se configura de manera desterritorializada (D'Aubeterre, 2000b), siendo fuente de tensión para ambos cónyuges. La preocupación por la entrega periódica de ingresos (los "migradólares") a los miembros de la familia que se queda en la localidad de origen, para poder solventar los gastos del grupo familiar, es una de las mayores fuentes de conflicto.

En su caso, Ixmucané, quién migró en dos ocasiones a Cancún, México, dónde conoció a su actual esposo, refugiado en territorio mexicano de niño junto a sus padres en tiempos del conflicto armado interno, narra su vivencia conyugal, ya de regreso en su comunidad, en Colotenango, ahora que su marido trabaja en Tenessee, en los "Estados":

Nosotros estamos unidos no más. Mi hijo mayor ya lleva 16 años, tal vez 16 años digo yo, llevo con él, o quién sabe... Pero yo no le entiendo él que por qué no manda él, dinero. ¿Por qué él no manda dinero? Esa es la duda que yo tengo con él. Yo le dije a él, cuando llamó, pero él dijo que sí, "Te voy a mandar. Y ahí cuentas de cuántos años llevamos de estar unidos, ya cuántos años... ¿Cómo vas a pensar, y además si ya estamos viejos, cómo vas a pensar que nos vamos a separar?" Entonces dijo él que sí; bueno, y él qué le cuesta decir que si, y a la mera hora... Yo no le creo, porque no puede ser eso, más de tres meses que él no está trabajando. Yo lo que pensaba, estar con mis hijos. Hay personas que dan buen consejo, y hay personas que me dicen, "Ah, y iporqué no buscas otro y porqué no vas con otro?" Bueno, yo nada más recibo las palabras de ellos, yo no les digo nada. Pero yo por mi parte, es cuidar a mis hijos, es crecer a mis hijos, no pienso nada de irme con otro, nada. Yo nada más pienso cómo voy a crecer a mis hijos. Sólo eso pienso yo. Entonces mejor lo que pongo a pensar, o traer un corte para tejer, y con eso tal vez, salgo yo, pienso que si... Tal vez con eso podría sacar el estudio de ellos. Entonces le dije a él, cuando llamó: "Sí, le digo, yo te entiendo, pero la cosa es que Ud. parece que ya no quiere Ud. a tus hijos, ni a mí. Entonces Ud. me podría decir la verdad, si Ud. no quiere mandar, pues mejor diga la verdad, si Ud. no quiere mantener a sus hijos, pues yo lo hago icómo voy a hacer? Voy a luchar, de todos modos voy a luchar.

En la búsqueda de alternativas para dar solución a su nueva situación vital, sin ingresos regulares, Ixmucané, esposa de migrante, describe la 
búsqueda de soluciones consensuadas con su esposo, y la toma de decisión personal de irse de la casa de sus suegros, para regresar a un espacio más seguro económica y afectivamente, cerca de su madre.

Y viera que por eso regresé yo con mi mamá porque nos faltaba dinero, él no nos daba. Ya no mucho manda. Un año estuvimos sin dinero, él nos llama, nada, nada... y mejor me dijo mi mamá, "Véngase", dijo. Y nos vinimos nosotros, con 4 hijos. Ellos (sus suegros) no dijeron nada, y me vino yo para acá. El no se enojó, nada más él me preguntó que porqué había venido yo acá, entonces yo le dije que por motivo de falta de dinero, "Y como Ud. no ha mandado, por eso nosotros venimos", le dije a él. Y no me dijo él nada. "Pero yo no te dije que te fueras", dijo. "Sí, le dije, Ud. no me dijo, pero cómo vas a pensar que estamos viviendo sin dinero. Gracias a Dios que mi mamá me dejó esa casa, mejor venir a vivir aquí." El no dijo nada... aceptó. No le gustó, pero como yo le dije "Ud. tiene la culpa. ¿Yo para qué puedo regresar por vos?, si...." Entonces él no dijo nada. El dijo que sí va a regresar (a casa), pero saber cuándo...sí, saber cuándo... Y él ahorita está sin dinero, ni para viajar. Y si regresa, estoy pensando... ipara qué vas a ir a pegar a tras de él? Pero yo le dije a él que si él quiere estar aquí... y seguir juntos. Sí él dice que si, unos días allá, unos días aquí, por mi mamá, pues no puedo dejar, y si él no quiere pues, es problema de él... si, es problema de él. Sí, pero yo qué voy a hacer porque no puede ser que voy a dejar a mi mamá sola. Yo sé que él lo va a entender. Uno diciendo pues, y cuando viene, el va a ver: iquién va a quedar con mi mamá? Entonces le digo yo a él que si él quiere, pues unos días aquí y unos días allá. Si hay trabajo aquí, venimos; si hay trabajo allá, nos vamos para allá. Por si él llega a venir, pues, porque ya lleva 7 años que él está allá.

\section{Conclusiones}

EnelmunicipiodeColotenango, los procesos migratorios, el acceso a la educación y la equidad en los espacios de participación social, han significado transformaciones sociales y económicas de gran relevancia para la subsistencia de los grupos familiares. En el mismo proceso, se evidencian modificaciones en las pautas de relación intergenéricas que van construyendo y definiendo diferentes normas sociales y culturales que regulan los procesos de negociación de género. También se observan participaciones diferenciales entre mujeres y hombres a la hora de negociar sobre las propias normas sociales, y sobre lo que es, o no, factible de ser negociado en el ámbito doméstico (familiar) como en el extradoméstico (o público) (Agarwall, 1999).

El análisis de algunos sujetos del entramado social pone de relieve la forma en que, situados como nudos en la red, vehiculan flujos discursivos desde ciertos espacios sociales hasta otros, ya sea a escala local, regional o global. A su vez, la forma en que sobre el constante ir y venir de personas, circulan discursos en el seno de la comunidad extendida, y cómo van además facilitando, o no (en el caso de la promotora local y del maestro bilingüe intercultural, respectivamente) poder y contrapoderes en las temáticas de género y educación.

Por una parte, en este análisis propuesto, en la articulación local/global, cada uno de los sujetos sociales concebidos como "nudo del entramado social" tiene complejas determinaciones, en función de su historia en la comunidad, sus identidades y sus intereses, por lo que habría que representárselos como "nudos móviles" (y no fijos). En este sentido no se trata de un sujeto único, ya que evidentemente no ejerce las mismas prácticas, ni se encuentra en una misma situación discursiva una promotora de ONG joven, que una promotora líder histórica de su comunidad, o una promotora que a su vez sea comadrona.

Por otra parte, se puede considerar como eje analítico transversal para los tres sujetos/nudos 
propuestos, la categoría de trabajo, entendida ésta como práctica económica, social y política. Así, mientras el trabajo, en el caso del coyote y del maestro bilingüe intercultural es una condición naturalizada y deseada socialmente, en el caso de la promotora se trata de un reposicionamiento social. La promotora se constituye en trabajadora y se reapropia de una voz autorizada que se fortalecerá en la articulación con sus otras identidades, ya sea como líder, hija, esposa, y que puede facilitar la resolución y negociación de conflictos en el ámbito doméstico. Efectivamente, en su condición de trabajadora, muchas mujeres migran solas hacia las fincas de café o al norte a trabajar, lo que determina nuevos escenarios familiares. De entre las que se quedan en la comunidad, son muchas las que ya no sólo resuelven sus conflictos con el esposo migrante al norte, sino también con la familia del esposo.

A nivel organizativo, la promotora se levanta como figura clave en la articulación de nuevas y creativas apropiaciones de los discursos sobre género y los derechos de la mujer, posibilitando el diálogo y la construcción de nuevos espacios sociales con los dirigentes varones de las organizaciones comunitarias que tienden a la resolución conjunta de los conflictos comunitarios, familiares y conyugales, fortaleciendo el tejido social mam. Con todo este es un trabajo que se inicia, en el que cabe también analizar otros sujetos/nudos que tienen un rol protagónico y tal vez menos visibilizado en las comunidades mayamam de Huehuetenango, en la relación conflictiva y complementaria de poderes y contrapoderes de género.

\section{Notas}

${ }^{1}$ Este trabajo es producto de la investigación etnográfica "Violencia doméstica y conflictos conyugales en comunidades maya-mam de Huehuetenango, Guatemala", realizada en el marco del Doctorado en Antropología Social en el Instituto de Investigaciones Antropológicas de la UNAM.
${ }^{2}$ Se adopta la visión del acto de lenguaje como una puesta en escena del mundo por parte del sujeto productor de discurso. En esta perspectiva, se sigue a diversos lingüistas de lo que se ha dado en llamar "la escuela francesa de análisis del discurso" (Pêcheux, 1969; Charaudeau, 1983; Vignaux, 1976), a sociólogos como Goffman (1970) y Bourdieu (1985), y a filósofos como Michel Foucault $(1970,1971)$.

${ }^{3}$ Los datos primarios obtenidos por Castillo et al. arrojan que $90 \%$ de trabajadores encuestados provenían del fronterizo departamento de San Marcos; cifra que puede variar por región de la unidad empleadora, pero que tiende a confirmar la procedencia desde el occidente del país.

\section{Bibliografía}

Agarwal, Bina (1999), "Bargaining and Gender Relations: Within and Beyond the Household", en Feminist Economics, vol. 3, núm.l, pp: 1-5l.

Álvarez, Gerardo, Álvarez, Andrea y Facuse, Marisol (2002), "La construcción discursiva de los imaginarios sociales: el caso de la medicina popular chilena", en Onamazein, núm. 7, Pontificia Universidad Católica de Chile, pp. 145-160.

Álvarez, Gerardo (2007), “Anticonceptivo de emergencia, aborto y otras píldoras: el contexto social de la argumentación", en Revista de Lingüística Teórica y Aplicada, vol. 45(1), I Sem. Universidad de Concepción, Concepción, pp. 45-66.

Ángeles, Hugo (2002), "Migración en la frontera MéxicoGuatemala. Notas para una agenda de investigación”, en Kauffer, Edith (editora) Identidades, migraciones y género en la frontera sur de México, México: El Colegio de la Frontera Sur, San Cristóbal de Las Casas, Chiapas, México, pp. 193-214.

Aragonés, Ana Maríay Dunn, Timothy(2005), "Trabajadores indocumentados y nuevos destinos migratorios en la globalización", en Revista Política y Cultura. Primavera, núm. 23, México: UAM-Xochimilco, pp. 43-65. 
Ariza, Marina (2007), "Itinerario de los estudios de género y migración en México", en El país transnacional. Migración mexicana y cambio social a través de la frontera, México: UNAM, pp. 453-5ll.

Arizpe, Lourdes (1978), Migración, etnicismo y cambio económico. Un estudio sobre migrantes campesinos a la ciudad de México, México: COLMEX.

Baeza, Manuel Antonio (2000), Los caminos invisibles de la realidad. Ensayo de sociología profunda sobre los imaginarios, Santiago de Chile: RIL.

Berger, Peter y Thomas, Luckmann (1987), La construcción social de la realidad, Buenos Aires: Amorrortu.

Castillo, Manuel Ángel (1993), Migraciones de indígenas guatemaltecos a la frontera sur de México. Boletín Mayo, núm. 18, Centro de Estudios Urbanos y Regionales, Universidad de San Carlos de Guatemala, Ciudad de Guatemala.

Castoriadis, Cornelius (1975), L'institution imaginaire de la société, Paris: Editorial du Seuil.

Cojtí, Demetrio Waq’i Q'anil (2007), "El proceso de mayanización y el papel de la educación escolar", en Bastos, Santiago y Cumes, Aura (coords.) Mayanización y vida cotidiana. La ideología multicultural en la sociedad guatemalteca, vol. 3, Análisis específicos, Guatemala: FLACSOCIRMA, pp. 9-60.

D’Aubeterre, María Eugenia (2000a), “Mujeres y espacio transnacional: maniobras para renegociar el vínculo conyugal", en Barrera y Oehmichen (eds.) Migración y relaciones de género en México, GIMTRAP y UNAM/IIA, México, pp. 63-85.

D’Aubeterre, María Eugenia (2000b), El pago de la novia, Colegio de Michoacán, Universidad Autónoma de Puebla, Instituto de Ciencias Sociales y Humanidades, Zamora.

Duarte, Rolando y Coello, Teresa, 2007, La decisión de marcharse. Los pueblos indígenas migrantes de Guatemala y Chiapas, Consejería en Proyectos, Ciudad de Guatemala.
Foucault, Michel (1971), L'ordre du discours, Gallimard, Paris.

Garduño, Everardo (2003), "Antropología de la frontera, la migración y los procesos transnacionales”, en Revista Frontera Norte, vol. 15, núm. 30, Colegio de la Frontera Norte, Tijuana, pp. 65-89.

Geertz, Clifford (2000), La interpretación de las culturas, Barcelona: Gedisa.

Hernández, Aída (2008), "Descentrando el feminismo. Lecciones aprendidas de las luchas de las mujeres indígenas de América Latina", en Etnografías e historias de resistencia. Mujeres indígenas, procesos organizativos y nuevas identidades políticas, CIESAS-UNAM, México: La Casa Chata, pp. 15-40.

Hernández, Elsa (2009), Al otro lado están los hombres. Migración internacional y reconfiguración de relaciones de género en Huehuetenango, Guatemala, Tesis para optar al Grado de Maestra en Antropología Social, Universidad Iberoamericana, México.

Hondagneu-Sotelo (2007), "La incorporación del género a la migración: no sólo para feministas ni sólo para la familia", en Ariza y Portes (coordinadores) El país transnacional. Migración mexicana y cambio social a través de la frontera, México: UNAM, pp. 423-451.

Mendizábal, Sergio et al. (2007), El encantamiento de la realidad. Conocimientos mayas en prácticas sociales de la vida cotidiana, Dirección General de Educación Bilingüe Intercultural-Universidad Rafael Landivar, Guatemala.

Meneses, Guillermo (2007), "Los peligros del desierto en la migración clandestina por California y Arizona", en Pérez-Taylor, Olmos Aguilera y Salas Quintanal (eds.) Antropología del desierto. Paisaje, naturaleza y sociedad, México: UNAM-Colegio de la Frontera Norte, pp. 109-120.

Ordóñez Morales, César (1990), Migraciones de trabajadores guatemaltecos y crecimiento económico en el Soconusco, Chiapas, CIES, San Cristóbal de Las Casas, Chiapas. 
Trujillo, Silvia (2004), Por una vida sin violencia: Contribuciones del movimiento de mujeres, Encuentro nacional de estudios de género, FLACSO, Ciudad de Guatemala.
Valladares, León (1957), El hombre y el maíz. Etnografía y etnopsicología de Colotenango, México: CostaAmic.

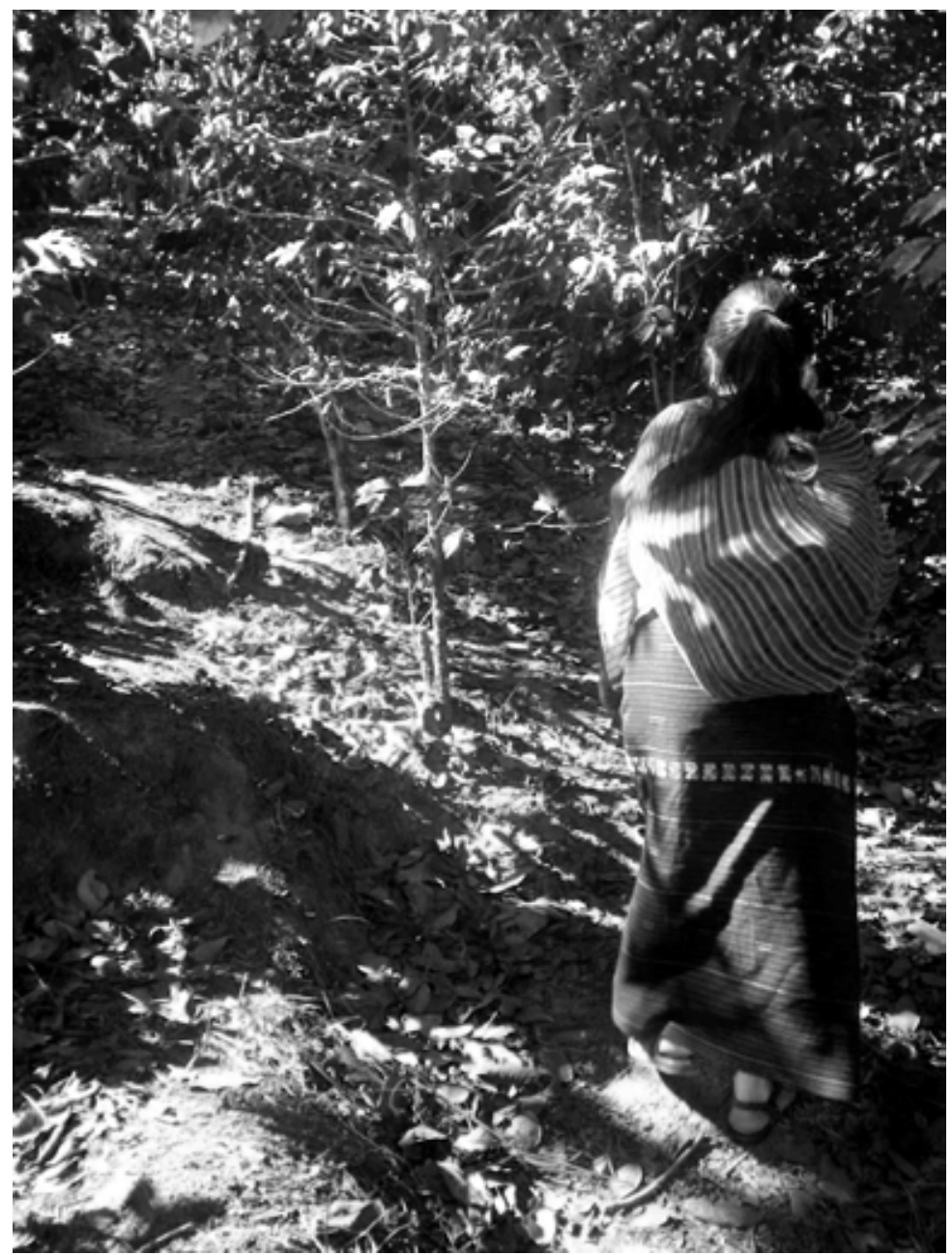

Trabajadora temporal maya-mam en cafetales FOTOGRAFÍA: Andrea Álvarez 


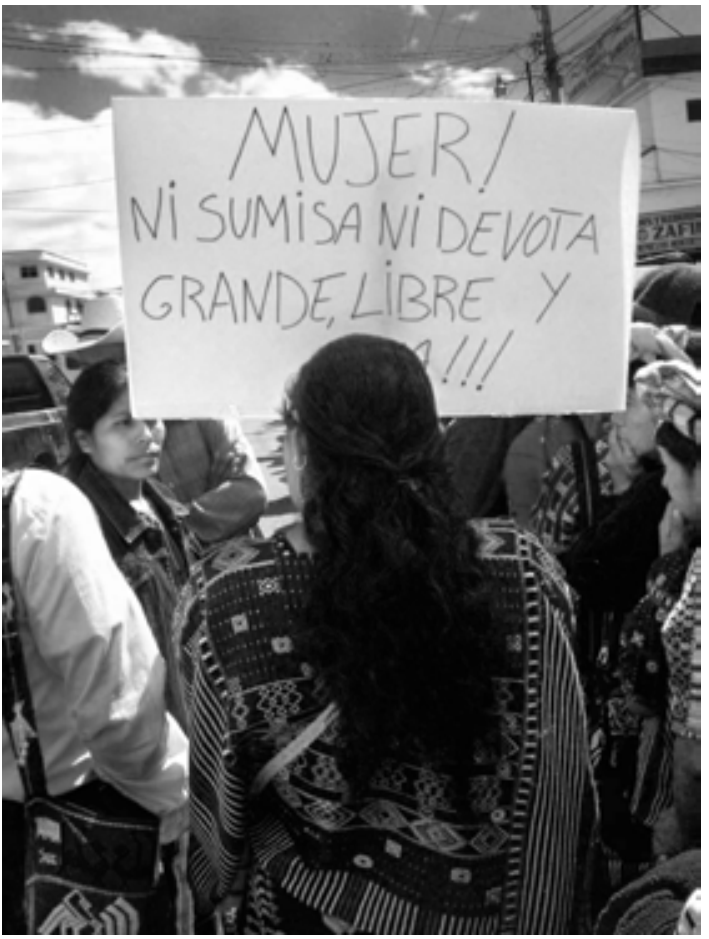

Discursos de género y de defensa de los Derechos de las mujeres FOTOGRAFIA: Andrea Álvarez

Promotora local desarrollando trabajo de discusión grupal FOTOGRAFÍA: Andrea Álvarez

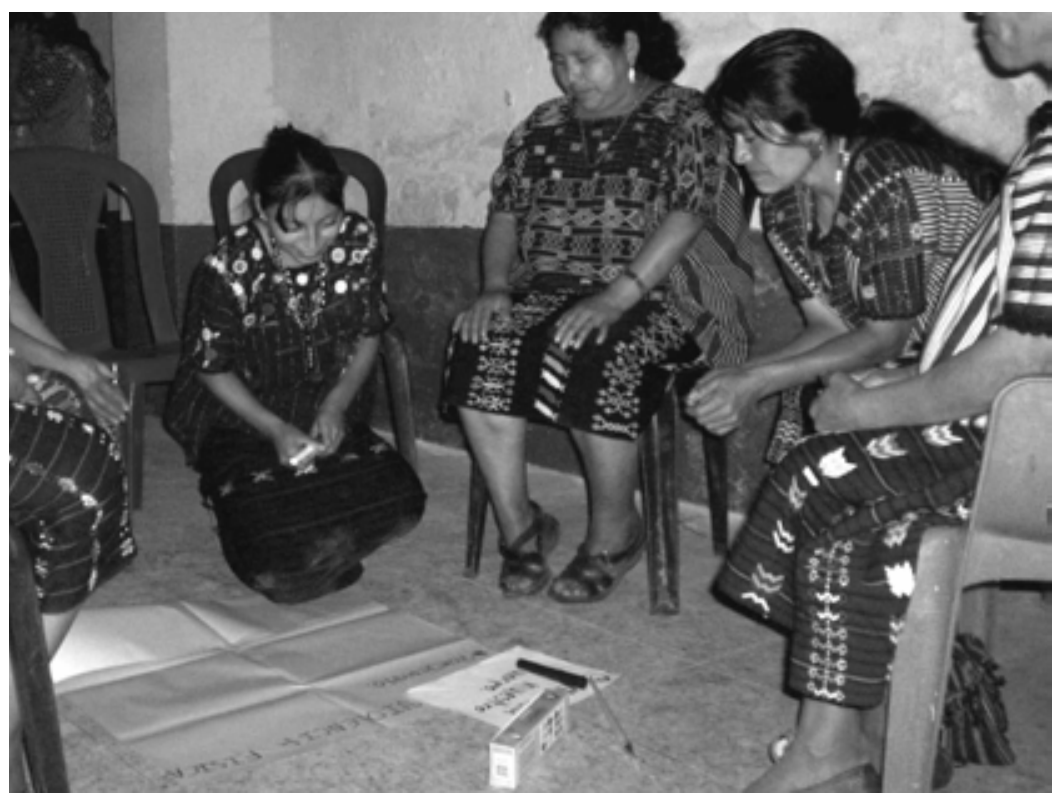

Revista LiminaR. Estudios sociales y humanísticos, año 8, vol. VIII, núm. 1, junio de 2010, San Cristóbal de Las Casas, Chiapas, México. ISSN: 1665-8027 